\title{
RIDGE PRESERVATION USING COLLAGEN CONE FOR IMPLANT SITE DEVELOPMENT: CLINICAL, RADIOGRAPHICAL AND HISTOLOGICAL STUDY
}

\author{
Maggie Ahmed Khairy*, Alshaimaa Ahmed ${ }^{* *}$ and Inass Abou Elmagd***
}

\begin{abstract}
Objectives: the aim of the study was to evaluate the clinical and histological outcomes of extraction socket grafted with collagen cone in comparison to extraction site that healed naturally for implant site development.

Patients \& Methods: Twenty-six healthy patients require extraction of a single rooted tooth participated in this study. They had been divided into 2 groups. In Group I (control), the extraction socket was left with no graft to heal with secondary intention. While in group II (study), the socket was filled with collagen cone. Implants were inserted in average of 3 months after socket grafting. Cone Beam CT (CBCT) images were done prior to implant insertion to asses height and width of the ridge as well as bone density. Core biopsies were taken during implant placement. While implant stability test (ISQ) were done right after the implant was placed
\end{abstract}

Result: The vertical bone changes at the grafted sockets were significantly lower $(\mathrm{p}<0.0001)$ when compared to non-grafted sockets. Moreover, the width reduction of the grafted sites was significantly lower $(\mathrm{p}<0.0001)$ than the non-grafted group. No significant difference was detected in RFA between two groups. Values of bone density was higher in the grafted sites.

Conclusion: the alveolar preservation with collagen cone is an effective way to maintain the ridge dimensions after tooth extractions.

Keywords: Socket preservation, Collagen cone, tooth extraction socket, alveolar ridge.

\section{INTRODUCTION}

After tooth extraction, the alveolar ridge undergoes unsteady resorption and atrophy especially during the first three months ${ }^{(1)}$. Those changes result in 50\% reduction in the buccolingual width of the alveolar bone, followed by considerable loss in the ridge height ${ }^{(1-4)}$.

A systematic review evaluated the dimensional changes of the alveolar ridge after tooth extraction and showed a mean reduction of $3.8 \mathrm{~mm}$ in width and $1.24 \mathrm{~mm}$ in height during the first six months ${ }^{(5)}$.

\footnotetext{
* Assistant professor of Oral and Maxillofacial Surgery, Faculty of Dentistry, $6^{\text {th }}$ October University, Egypt

** Lecturer of Oral and Maxillofacial Surgery, Faculty of Dentistry, Fayoum University, Egypt

*** Lecturer of Radiology, Faculty of Dentistry, Fayoum University, Egypt
} 
The order of bone resorption is predictable, the buccal aspect resorbing first, with high resorption rate taking place in width than height. Also, the mandibular bone resorbs faster than the maxillary. These results in a lingual shift of the crest of the bone, in relation to the original position of the tooth..$^{(5,6)}$

Changes which take place in the alveolar ridge after tooth extraction may compromise the prosthetic rehabilitation with either fixed or removable prothesis as well as implant supported restorations. These changes affect the optimal position of the dental implant and affect the esthetic and functional outcome of the final restoration. ${ }^{(5-8)}$

Over the past decades, many surgical procedures were introduced to maintain the ridge profile in aesthetic sites, and to prevent alveolar ridge collapse, preserving adequate dimensions of bone to facilitate correct implant placement. ${ }^{(9)}$

In many clinical studies, several methods have been used to counteract the remodeling pattern of the alveolar ridge such as socket grafting with autogenous bone grafts, demineralized freeze-dried bone allografts (DFDBA), deproteinized bovinebone mineral (DBBM), other xenografts, alloplasts, and bone morphogenic proteins (BMP). Moreover, guided bone regeneration (GBR) procedures with or without bone grafts, with resorbable or non-resorb able barriers, have also been used to preserve the alveolar socket. ${ }^{(9-16)}$

During healing of the grafted extraction socket, a foreign body reaction to the graft particles causes delayed healing response compared to the nongrafted sites in which the newly formed woven bone occupies most of the ridge space. However new bone formation appears to be similar in both grafted and non-grafted extraction socket at three months except for remaining graft particles that still occupy part of the ridge volume. the residual graft particles may not be fully resorbable and could affect early osseointegration of implant. ${ }^{(17,18)}$
Unlike other grafting material, the collagen sponge is highly biocompatible and fully resorb although the crosslinked collagen resorbs more slowly. Moreover, the collagen sponge support both hard and soft tissue healing. ${ }^{(19)}$

The aim of the current study was to evaluate the clinical and histological outcomes of extraction socket grafted with collagen cone in comparison to extraction site that healed naturally for implant site development.

\section{PATIENTS AND METHODS}

\section{Patients recruitments and pre-surgical preparation:}

Twenty-six healthy patients require extraction of a maxillary single rooted teeth participated in this study. Their age ranged from 20 to 50 years. The participants were recruited from Outpatient clinics of Oral and Maxillofacial Surgery Department, Faculty of Dentistry, Fayoum University.

Patient selection was based on certain inclusion and exclusion criteria. The inclusion criteria include age $>18$ years, with no systemic disease(s), and, in need to extract a single rooted tooth and an implant supported restoration. While the exclusion criteria include allergy, smoking, alcoholism and drug abuse, pregnancy, or nursing mothers. Patients with removable prothesis were also excluded. Patients with acute abscesses or active infections localized in the proximity of the surgical field, patients with scarred mucosa at the surgical site and patients who had malignant diseases or other diseases treated with radiotherapy or chemotherapeutic agents (chemotherapy) during the past 5 years were also excluded.

Completed medical and dental history was taken for all patient and alveolar bone around the teeth was evaluated using CBCT. Patients were fully informed about the treatment procedures, followup examinations and complications of surgical procedures. Informed consent was obtained from each patient prior to participation in the study. 


\section{Grouping and randomization:}

Following enrollment, participants were randomly assigned to one of treatment groups. The patients were equally allocated in two groups. In group I, the extraction socket was left without grafting as control group while in group II, the extraction socket was filled with collagen cone as study group.

All Patients were subjected to a standardized surgical protocol by the same surgeon and another operator carried out the postoperative measurements.

\section{Surgical techniques:}

Tooth extraction was performed under local anesthesia without flap elevation. Periotomes and luxators (Directa, Sweden) were used during the extraction procedures to minimize the trauma to gingiva and bone. All sockets were thoroughly curetted to remove granulation tissue, followed by irrigation and rinsing with sterile saline.
In Group I (control), the extraction socket left with no graft to heal with secondary intention. While in group II (study), the socket was filled with collagen cone (Parasorb ${ }^{\circledR}$ Cone, Resorsorba, Winsford, UK). An Figure of eight tension-free nonresorbable 4-0 sutures (Black Silk, Ethicon, Johnson \& Johnson, Somerville, NJ, USA) was placed over the filled socket to stabilize the cone in the socket and to achieve soft tissue stability. All sites were left uncovered without obtaining primary closure to heal by secondary intention.

The patients received detailed verbal and written postoperative instructions. Antibiotic therapy consisting of $1 \mathrm{~g}$ amoxicillin (Augmentin $1 \mathrm{gm}$, Smithline Beecham Pharmaceutical Co., Bentford, England) every $12 \mathrm{~h}$ for 4 days and mouth rinsing with $0.2 \%$ chlorhexidine (Hexitol mouth wash, the Arab Drug Co., Cairo, Egypt) every 8 h for 10 days were prescribed. The suture was removed one week postoperatively. (Fig. 1)
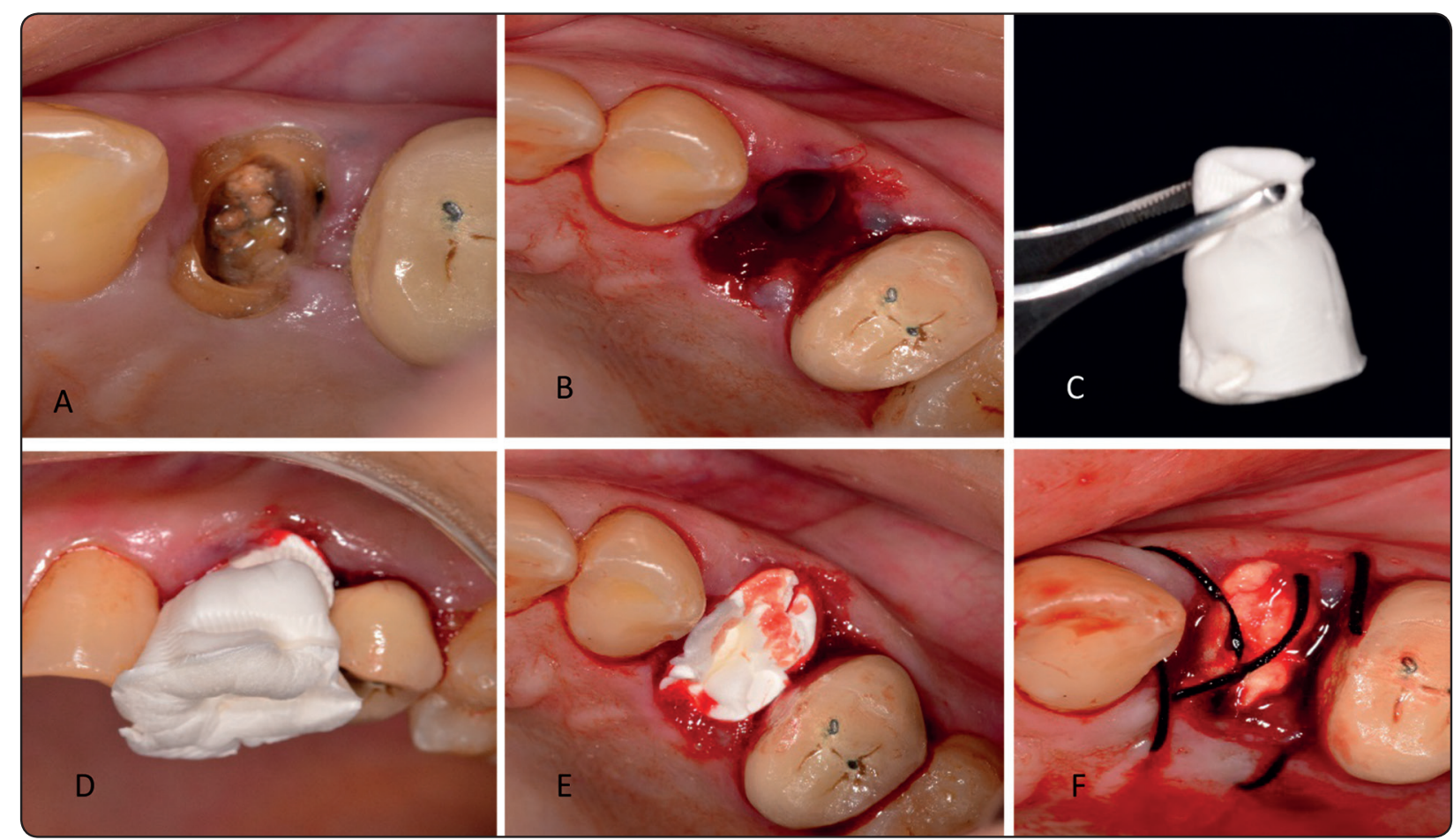

Fig. (1) a. preoperative Clinical view. b. Post-extraction view of the socket. (minimal trauma to the soft tissue and no flap reflection on the surgical site.) c. Collagen cone before placement. d \& e. collagen cone condensed in extraction sockets f. black silk sutures placed with tissue approximation and no releasing incision in the flaps. 


\section{Surgical Re-entry:}

After 3 months, the sites were reentered for implant placement. Prior to surgical intervention CBCT scan was obtained. A full thickness mucoperiosteal flap was elevated to expose the regenerated hard tissue. A bone core biopsy was taken with a minimum depth of $7 \mathrm{~mm}$ from the center of the site using a trephine drill with a diameter of $2.3 \mathrm{~mm}$ (Komet Inc., Lemgo, Germany). (Fig. 2)

After the harvesting of the bone sample, the preparation of the bony bed was completed at the same site and a dental implant (TRI ${ }^{\circledR}$ implants, TRI Dental implants, Bösch, Germany) was placed according to the manufacturer's surgical protocol. (Fig. 3)

Resonance frequency measurements for each implant were performed immediately after the implant placement via the Osstell ISQ system (Osstell@, integration Diagnostic AB, Goteborg, Sweden.). A magnetic peg Suitable for each implant were inserted using a plastic screw driver. The probe of the device was held $1 \mathrm{~mm}$ from the peg at a 90 angle. Two measurements were made for each implant from buccolingual and mesiodistal directions and the average of registered ISQs was recorded as one value. (Fig 5)

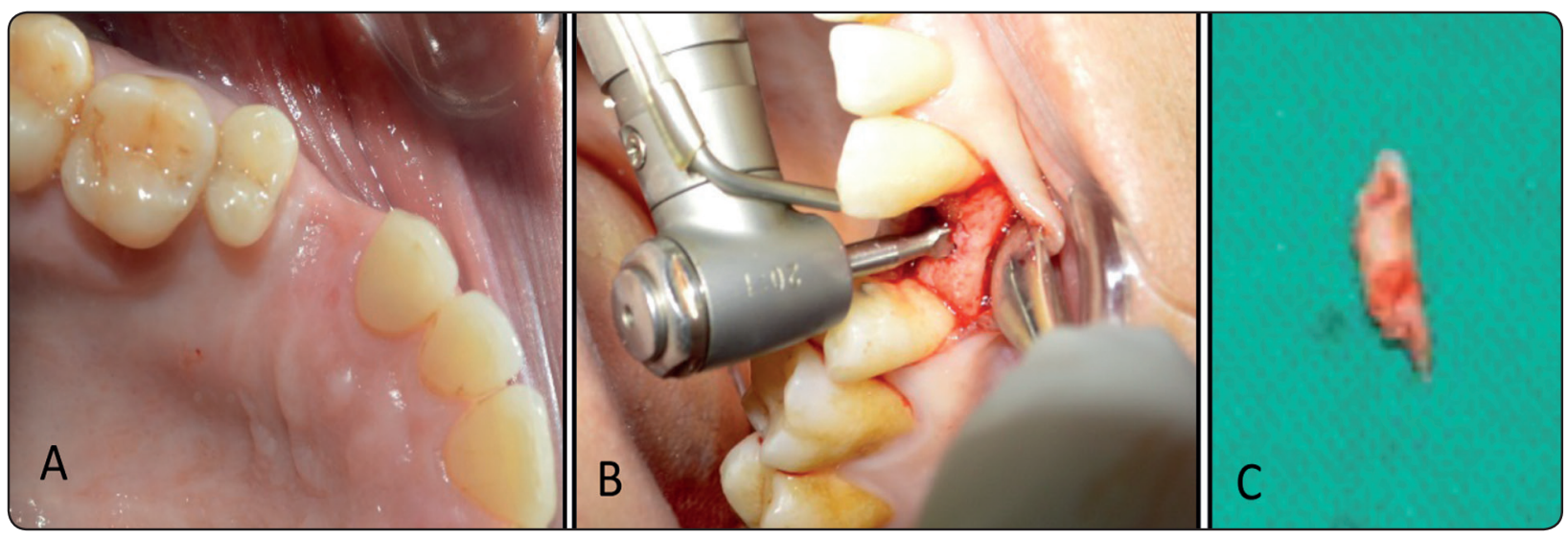

Fig. (2) a. Clinical postoperative view after 3 months. b. Core biopsy harvesting before implant placement. c. Core biopsy after harvesting

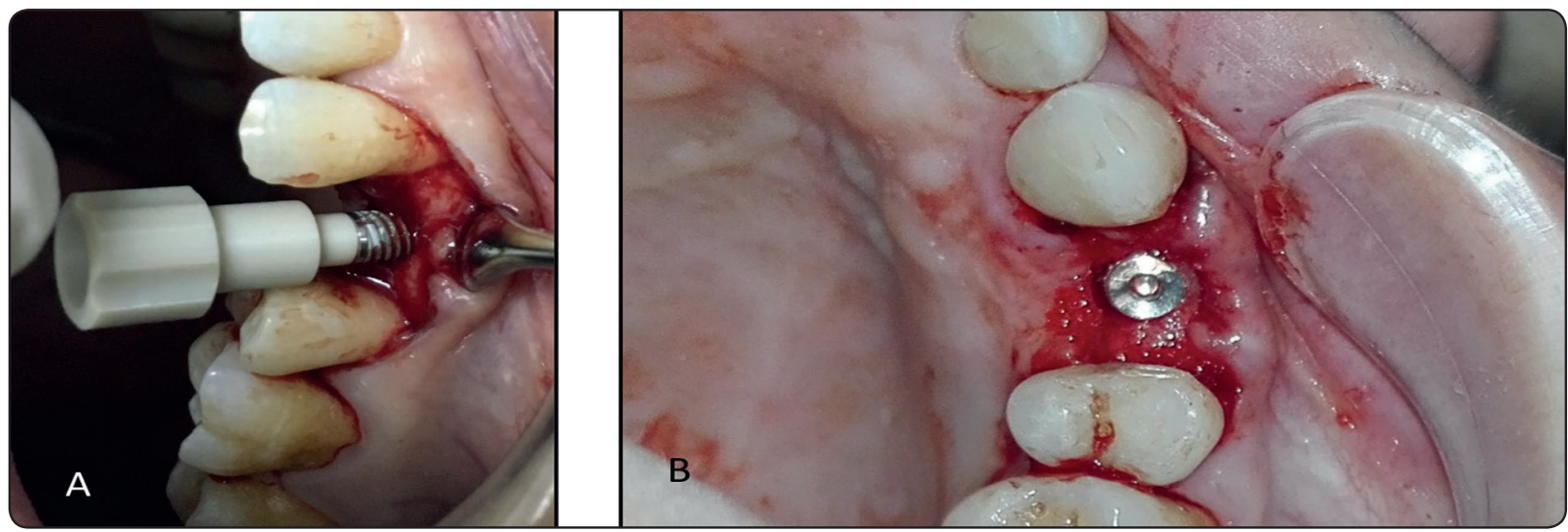

Fig. (3) a. Implant Placement b. Implant in place 


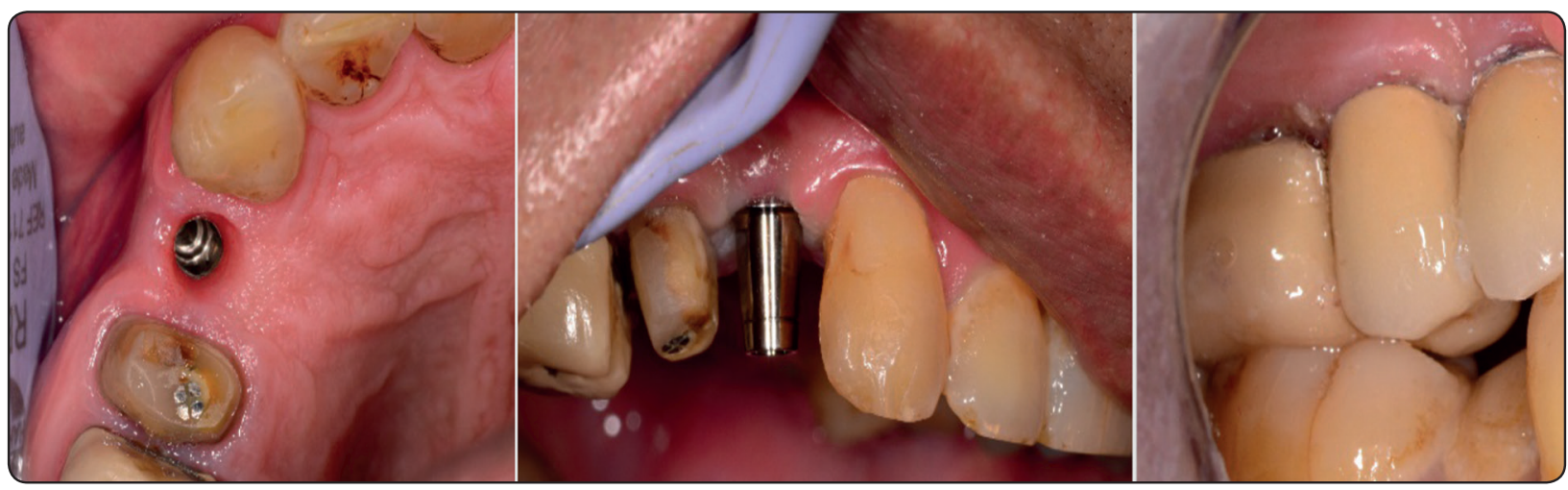

Fig. (4) A photograph showing the final restoration.

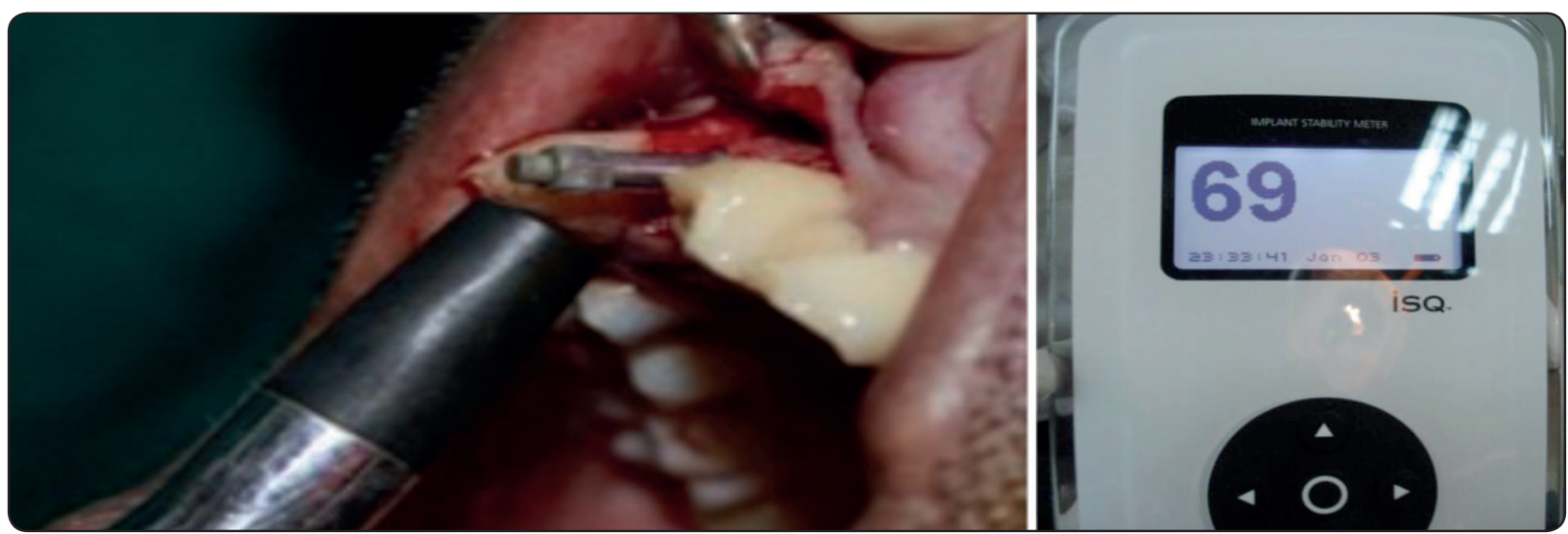

Fig. (5) Implant stability Measurement

\section{Assessment of ridge changes by cone beam CT:}

The area of interest was identified in accordance with the site of extraction. Axial correction of the view was performed in conformity with angulation of the alveolar ridge. Buccolingual/palatal width of the alveolus was determined $2 \mathrm{~mm}$ below the alveolar crestal level before tooth extraction and at the time of implant placement. Also, the height of the alveolus was measured before the tooth extraction and at the time of implant placement. (Fig. $6 \& 7$ )

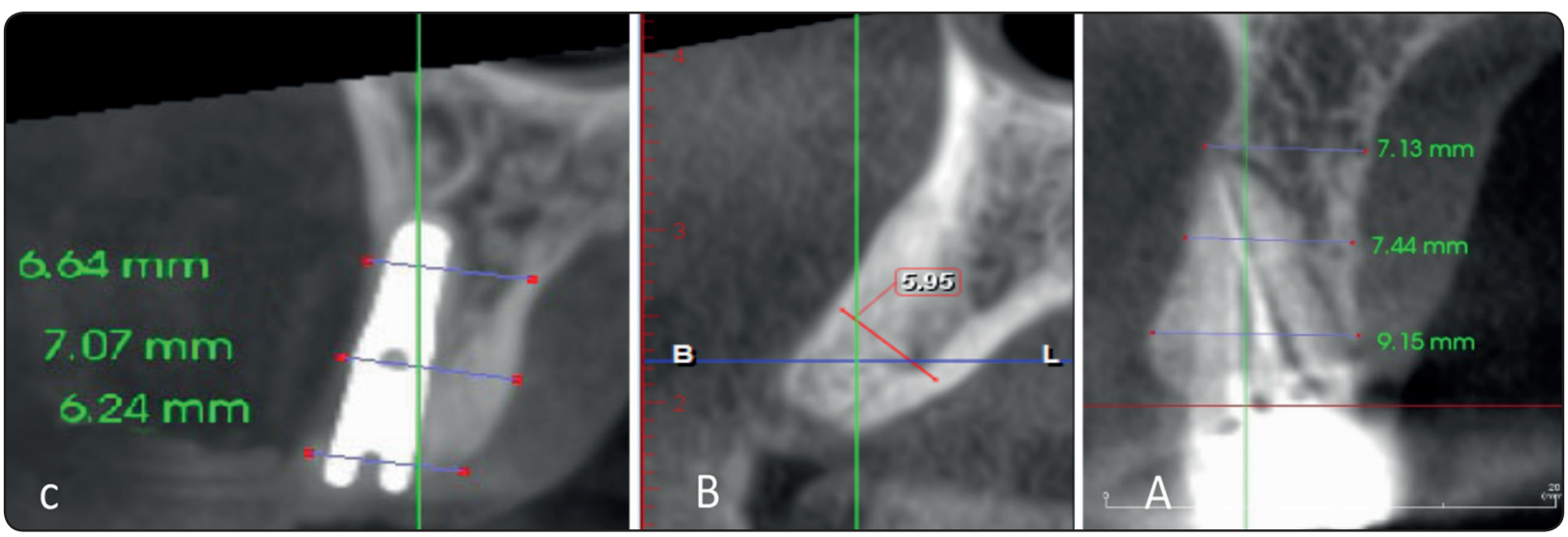

Fig. (6) CBCT image Showing a- before extraction b- after 3 months c- after implant Placement (Study Group) 


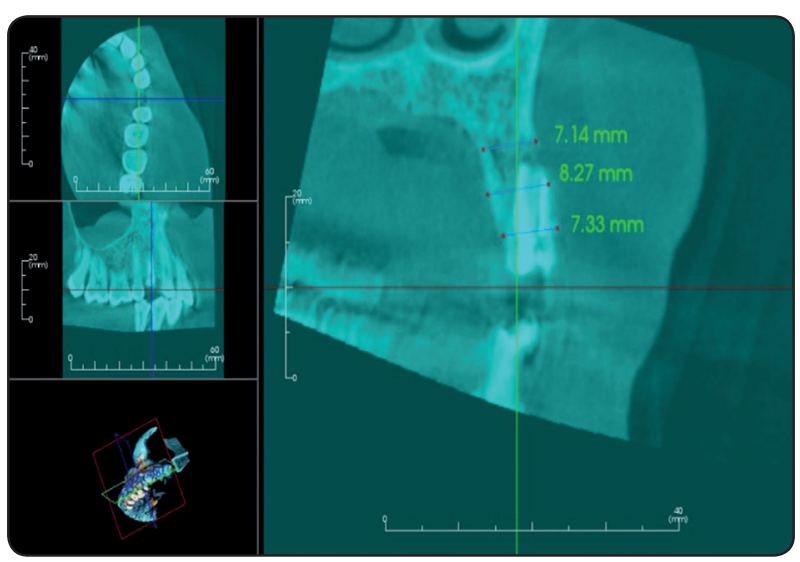

Fig. (7) Preoperative evaluation on CBCT.

The bone density was measured using software of Planmeca (Romexis Planmeca, Planmeca, Finland). For this purpose, Patients in both the study and the control groups received CBCT before the time of implant placement.

\section{Histological processing}

The harvested bone biopsies were decalcified in ethylene diamine tetra acetic acid (10\%) for a period of two weeks. After dehydration in graded series of ethanol, the specimens were embedded in paraffin and sectioned by high-speed rotating blade microtome; the sections were subsequently ground down to about 50-100 $\mu \mathrm{m}$ and stained with haematoxylin-eosin stain. The histomorphmetric analysis was done under magnification of $\mathrm{x} 40$ and $\mathrm{x} 100$.

\section{Statistical analysis of the data}

Data were fed to the computer and analyzed using IBM SPSS software package version 20.0. Data were fed to the computer and analyzed using IBM SPSS software package version 20.0. (Armonk, NY: IBM Corp). The Kolmogorov- Smirnov, Shapiro and D'agstino tests were used to verify the normality of distribution of variables, Comparisons between groups for categorical variables were assessed using Chi-square test (Fisher or Monte Carlo). Student t-test was used to compare two groups for normally distributed quantitative variables. Mann Whitney test was used to compare between two groups for abnormally distributed quantitative variables. Significance of the obtained results was judged at the $5 \%$ level.

\section{RESULTS}

A total of twenty- six patients was recruited in the present study and they are equally allocated by random distribution into 2 groups $(n=13$ patient per group). Eleven patients were males (42.3\%) and Fifteen were females $(57.7 \%)$ their mean \pm SD age was $36.2 \pm 9.30$ (range 22-50). Only one tooth per patient was treated. All patients completed the follow-up examination period, therefore no dropout in the study data. Tooth sites were distributed as follows: 18 premolars, 4 maxillary canines, 2 lateral incisors and 1 central incisors. Reasons for extraction includes fracture $(\mathrm{n}=5)$, extensive caries $(n=7)$ and endodontic failure $(n=14)$. Table (1)

TABLE (1): Patients Demographic Data per group

\begin{tabular}{|c|c|c|c|}
\hline & $\begin{array}{l}\text { Group Study } \\
\quad(n=13)\end{array}$ & $\begin{array}{l}\text { Group Control } \\
\qquad(\mathbf{n}=13)\end{array}$ & p \\
\hline \multicolumn{4}{|l|}{ Sex } \\
\hline Male & $5(38.5 \%)$ & $6(46.2 \%)$ & \multirow{2}{*}{0.691} \\
\hline Female & $8(61.5 \%)$ & $7(53.8 \%)$ & \\
\hline Age & $36.8 \pm 9.3$ & $36 \pm 9.4$ & 0.819 \\
\hline $\begin{array}{l}\text { Tooth to be } \\
\text { extracted }\end{array}$ & $\begin{array}{c}10 \text { premolars } \\
2 \text { canines } \\
1 \text { central Incisors }\end{array}$ & $\begin{array}{c}8 \text { premolars } \\
3 \text { canines } \\
2 \text { Lateral Incisors }\end{array}$ & 0.766 \\
\hline
\end{tabular}

Qualitative data were described using number and percent, while normally quantitative data was expressed in mean \pm $S D$, abnormally distributed data was expressed in median (Min. - Max.) *: Statistically significant at $p \leq 0.05$

The healing was uneventful in all cases and similar in both groups. No signs of infection were noted with any patient. Most of the grafted sites achieved complete epithelial closure after 2 weeks. The surgical procedure was performed for both grafted and ungrafted sites without any 
complication in all patients. All implants were placed at precise position showing primary implant stability and implant sites had a good resistance to drilling clinically.

The mean and standard deviation of RFA at the time of implant insertion was calculated for each group and compared to each other.

The RFA measurement showed an ISQ of 65.8 \pm 4.5 as a mean value for the test group indicating the higher primary implant stability for grafted sites than the un grafted sited which showed ISQ of 63.6 \pm 4 as mean value of primary implant stability in the control group. However, RFA demonstrated a no statistical significant in primary stability in both the study group and the control group (Table 2).

\section{Assessment of ridge changes by cone beam CT:}

CBCT was performed before tooth extraction and at the time of implant placement. Ridge width and height reduction had been calculated.

Mean ridge width reduction before tooth extraction to implant placement was $1.3 \pm 0.3 \mathrm{~mm}$ and $2.5 \pm 0.4 \mathrm{~mm}$ respectively in the study and control group respectively. Accordingly, the mean ridge width reduction showed a statistically significant difference in both groups (Table2, Fig 6).

While Mean ridge height showed a reduction before tooth extraction to implant placement of 2.4 $\pm 0.5 \mathrm{~mm}$ and $3.3 \pm 0.5 \mathrm{~mm}$ respectively in the study and control group respectively. The ridge height reduction between the two groups showed a clinical significant difference. (Table2, Fig 7).

After 3 month of tooth extraction, the bone density had a mean of 802.2 $\pm 96.6 \mathrm{HU}$ and $546.2 \pm 130.1 \mathrm{HU}$ in the study and control group respectively. Accordingly, the mean bone density showed a statistically significant difference between both groups (Table 2). However, the study group showed statistically significantly higher mean bone density than control group. (Table 2)
TABLE (2) Comparison between the two studied groups according to different parameters

\begin{tabular}{lccc}
\hline & $\begin{array}{c}\text { Group } \\
\text { Study } \\
(\mathbf{n = 1 3})\end{array}$ & $\begin{array}{c}\text { Group } \\
\text { Control } \\
(\mathbf{n}=\mathbf{1 3})\end{array}$ & $\mathbf{p}$ \\
\hline ISQ (implant Stability) & $65.8 \pm 4.5$ & $63.6 \pm 4$ & 0.214 \\
Width difference & $1.3 \pm 0.3$ & $2.5 \pm 0.4$ & $<0.001^{*}$ \\
Height difference & $2.4 \pm 0.5$ & $3.3 \pm 0.5$ & $<0.001^{*}$ \\
Bone density & $802.2 \pm 96.6$ & $546.2 \pm 130.1$ & $<0.001^{*}$ \\
\hline
\end{tabular}

Qualitative data were described using number and percent, while normally quantitative data was expressed in mean $\pm S D$, abnormally distributed data was expressed in median (Min. - Max.)

*: Statistically significant at $p \leq 0.05$

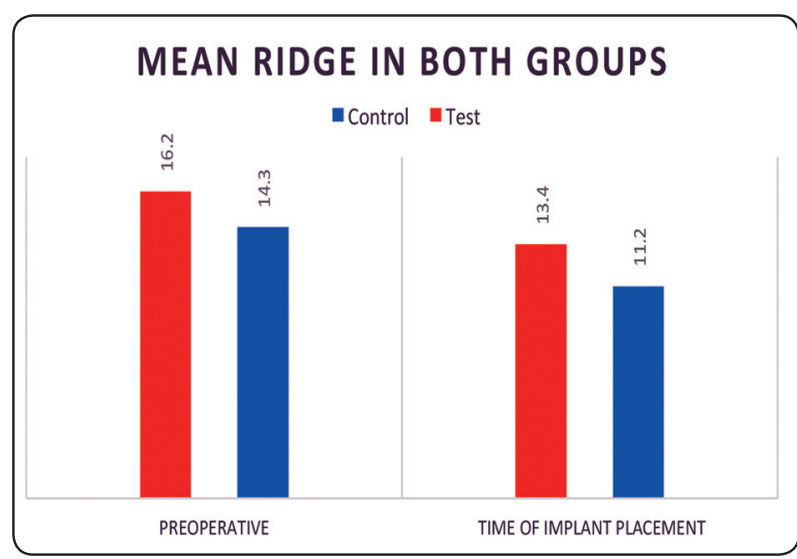

Fig. (8) Bar chart representing the mean ridge width in two groups

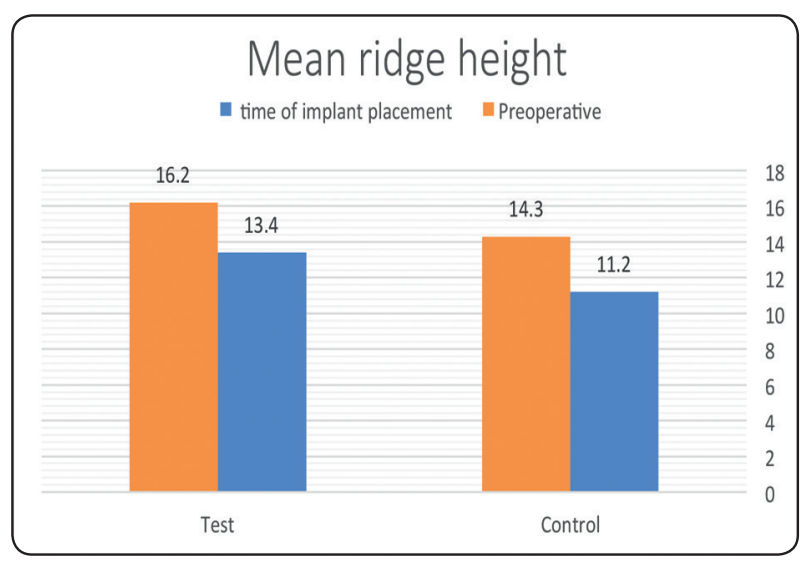

Fig. (9) Bar chart representing the mean ridge height in two groups 


\section{Histological Analysis}

A total of twenty- four bone biopsies was processed and analyzed (two bone biopsies were discarded because they were inadequate for histological processing).

The Hematoxylin and eosin stains sections revealed well organized bone trabeculae filling the socket and wide bone marrow with osteon and harversian system formation in addition to new bone formation with irregular trabeculae in both control and study group. Moreover, the sample from study group showed no residual graft material and well vascularized un-inflamed connective tissue.

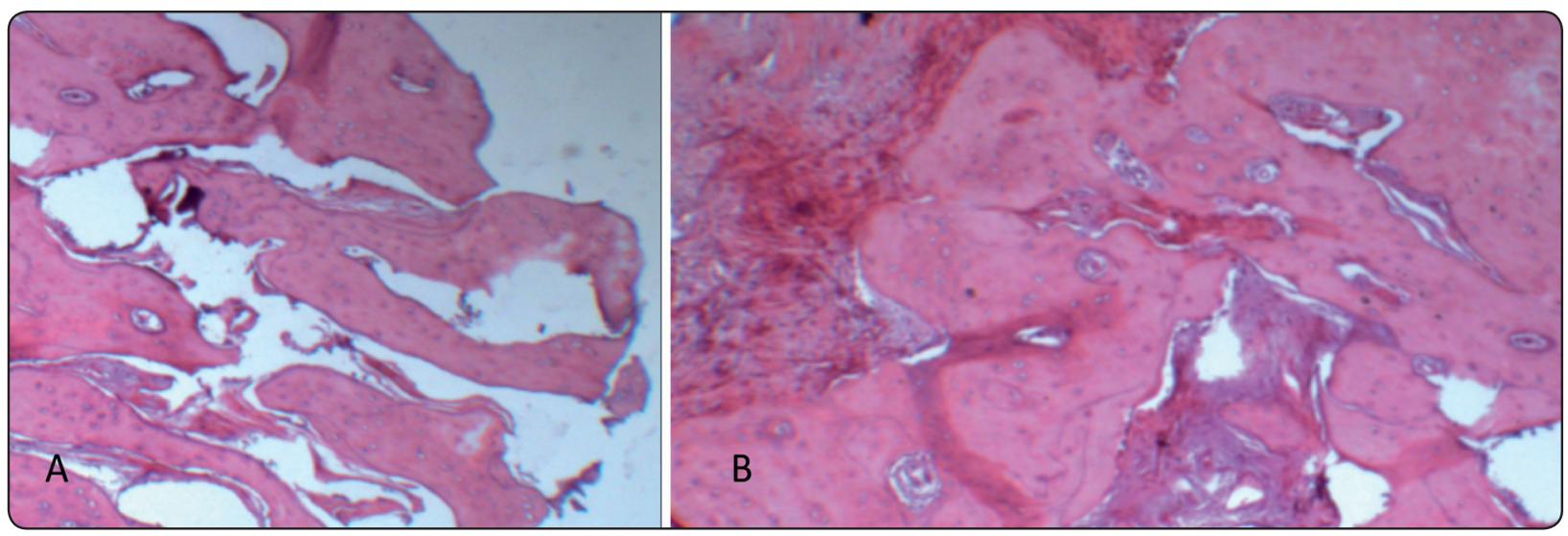

Fig. (10) Histological section of core biopsy taken from the site of extraction. a. Extraction site group I (Study), b. Extraction site group II (Control)

\section{DISCUSSION}

Ridge preservation of the extraction socket is essential procedure to preserve the ridge dimension for subsequent implant placement and to maximize the functional and esthetic outcome of the future restoration.

Ridge preservation techniques include the use of grafting materials of human, animal or synthetic origin, with or without the use of barrier membranes, to further optimize the functional and aesthetic restoration of dental implants. The grafting materials include: particulate autogenous chips, allografts, xenografts, and alloplasts. ${ }^{(4-10)}$

The current study aimed to report clinical, radiographicandhistologicaloutcomesofapplication of collagen cones as a socket preservation material compared to the naturally healing extraction socket.

The collagen cones were originally used to prevent complication in the third molar extraction sockets. The cones showed a positive effect on both soft and hard tissue healing. Subsequent studies had been conducted on the collagen effect on the bone healing and healing of extraction socket. ${ }^{(19,20)}$

In the present study, no clinical adverse reaction in any of the collagen grafted extraction sockets had been reported. This agreed with the results Cho et al ${ }^{(20)}$, who studied the postoperative complication rates for absorbable collagen sponge use in third molar extraction and concluded to that there was a relatively low incidence of complications in the study sample and recommend the use collagen sponges for the prevention of complications after third molar extraction.

Another study by Kim et al ${ }^{(19)}$, conducted to evaluate the healing outcomes after collagen plug insertion in extraction-related defects. They also stated that there was no adverse reaction during the healing period. Moreover, Hirota et al ${ }^{(21)}$ observed that bone healing sufficiently progressed with 
a collagen matrix compared to oxide cellulose insertion in extraction socket.

The uneventful healing is largely attributed to the ability of the collagen sponges to effectively contribute in wound protection, blood clot stabilization, and facilitation of granulation tissue formation for promoting wound healing. Moreover, collagen increases osteoblast function, the positive effects of a collagen plug are conceivable. ${ }^{(22,23)}$

Furthermore, Liu et al ${ }^{(24)}$ confirmed that the collagen exhibits a favorable biocompatibility, slow degradation as well as a preferable environment for osteoblastic adhesion and differentiation.

The present study showed that the collagen was more effective in controlling the ridge changes after tooth extraction when compared to the naturally healed extraction socket.

The socket that was grafted with collagen had a significantly lower reduction in width than that of the extraction socket that had healed naturally. Those data confirmed the finding from other studies in which horizontal bone resorption in grafted extraction socket was lower than that of extraction sockets that healed naturally. ${ }^{(17-20)}$

Moreover, Spinato el al (25) found greater horizontal bone loss at spontaneous healing sites when compared to grafted sites. They concluded that the ridge preservation procedures could counteract the remodeling pattern observed at the non-grafted sites thus reducing the risk of unfavorable resorption.

Furthermore, the present study showed that the use of a ridge preservation procedure could better preserve not only the ridge width but also the height when compared to tooth extraction alone. Moreover, the bone density in the grafted site showed a higher result from that of the naturally healed sockets.

On the other hand, Oghli \& Steveling ${ }^{(26)}$ inserted gentamicin-soaked collagen plugs in the socket and covered the socket entrance with a free gingiva graft. They observed no significant difference in ridge resorption between collagen plug-used sockets and naturally healed sockets. Also, Kim et al ${ }^{(19)}$ stated that the healing following the use of collagen plug in the extraction socket may correspond to the natural healing after extraction.

Moreover, Roman et al (27) used collagen membranes and 3D collagen matrices for ridge preservation with no comparison to natural healing. They concluded that collagen plugs showed biologically favorable responses in the healing event, use of collagen matrix alone might have limited effect on maintaining ridge dimension.

The histological evaluation showed a wellorganized bone trabecula filling the socket and wide bone marrow with osteon and harversian system formation in addition to new bone formation with irregular trabeculae in both control and study group. Moreover, the sample from study group showed no residual graft material and well vascularized un-inflamed connective tissue. The absence of the residual graft material indicates complete resorption of the material. This would suggest a more promising pattern for collagen- bone healing when compared to other graft material and confirm that the collagen was extensively resorbed after 12 weeks.

This was in accordance with Cardaropoli et al ${ }^{(28)}$ who graft the extraction socket with collagen sponge and with Bio-oss collagen graft. The histological evaluation showed a higher volume of newly formed bone in the collagen sponge grafted sites $(61.4 \%)$ versus bio-oss collagen grafted sites (46.7\%). Moreover, bio-oss particles were integrated within the newly formed bone.

Similar results within the histological evaluation of Kim et al (19) study showed that no remaining graft residual in collagen grafted sites.

In conclusion, the results of study showed that the alveolar preservation with collagen cone is an effective way to maintain the ridge dimensions after tooth extractions. 


\section{CONFLICTS OF INTERESTS}

The authors declare that there are no competing interests regarding the publication of this paper.

\section{REFERENCES}

1. Schropp L, Wenzel A, Kostopoulos L, Karring T. Bone healing and soft tissue contour changes following singletooth extraction: a clinical and radiographic 12-month prospective study. Int J Periodontics Restorative Dent. 2003; 23:313-23

2. Iasella JM, Greenwell H, Miller RL, Hill M, Drisko C, Bohra AA, et al. Ridge preservation with freeze-dried bone allograft and a collagen membrane compared to extraction alone for implant site development: a clinical and histologic study in humans. Journal of Periodontology 2003;74: 990-9.

3. Araújo MG, Silva CO, Misawa M, Sukekava F. Alveolar socket healing: what can we learn? Periodontol 2000. 2015; 68:122-34

4. Camargo PM, Lekovic V, Weinlaender M, Klokkevold PR, Kenney EB, Dimitrijevic B, et al. Influence of bioactive glass on changes in alveolar process dimensions after exodontia. Oral Surgery, Oral Medicine, Oral Pathology, Oral Radiology, and Endodontics 2000;90:581-6.

5. Tan WL, Wong TL, Wong MC, Lang NP. A systematic review of post-extractional alveolar hard and soft tissue dimensional changes in humans. Clinical Oral Implants Research 2012;23 Suppl 5:1-21.

6. Tallgren A. The continuing reduction of the residual alveolar ridges in complete denture wearers: a mixedlongitudinal study covering 25 years. Journal of Prosthetic Dentistry 1972; 27:120-32.

7. John V, De Poi R, Blanchard S. Socket preservation as a precursor of future implant placement: review of the literature and case reports. Compendium of Continuing Education in Dentistry 2007; 28:646-53.

8. De Risi V, Clementini M, Vittorini G, Mannocci A, De Sanctis M. Alveolar ridge preservation techniques: a systematic review and meta-analysis of histological and histomorphometrical data. Clin Oral Implants Res. 2015; 26:50-68

9. Darby, I., Chen, S. \& De Poi, R. Ridge preservation: what is it and when should it be considered. Australian Dental Journal 2008;53: 11-21
10. Aslan E, Gultekin A, Karabuda C, Mortellaro C, Olgac V, Mijiritsky E.Clinical,Histological, and Histomorphometric Evaluation of Demineralized Freeze-Dried Cortical Block Allografts for Alveolar Ridge Augmentation. J Craniofac Surg. 2016;27:1181-6

11. Hanser T, Khoury F. Extraction site management in the esthetic zone using autogenous hard and soft tissue grafts: a 5-year consecutive clinical study. Int J Periodontics Restorative Dent. 2014; 34:305-12

12. Troiano G, Zhurakivska K, Lo Muzio L, Laino L, Cicciù M, Lo Russo L. Combination of Bone Graft and Resorbable Membrane for Alveolar Ridge Preservation: a Systematic Review, Meta-analysis and Trial Sequential Analysis. J Periodontol. 2017; 12:1-17

13. Kakar A, Rao BHS, Hegde S, Deshpande N, Lindner A, Nagursky H, Patney A, Mahajan H. Ridge preservation using an in situ hardening biphasic calcium phosphate ( $\beta$-TCP/HA) bone graft substitute-a clinical, radiological, and histological study. Int J Implant Dent. 2017; 3:25

14. Barone A, Toti P, Quaranta A, Alfonsi F, Cucchi A, CalvoGuirado JL, Negri B, Di Felice R, Covani U. Volumetric analysis of remodelling pattern after ridge preservation comparing use of two types of xenografts. A multicenter randomized clinical trial. Clin Oral Implants Res. 2016;27: e105-15.

15. Mardas, N., Chadha, V. \& Donos, N. Alveolar ridge preservation with guided bone regeneration and a synthetic bone substitute or a bovine derived xenograft: a randomized, controlled clinical trial. Clinical Oral Implants Research 2010; 21:688-98.

16. Fiorellini, J.P., Howell, T.H., Cochran, D., Malmquist, J., Lilly, L.C., Spagnoli, D., Toljanic, J., Jones, A. \& Nevins, M. Randomized study evaluating recombinant human bone morphogenetic protein-2 for extraction socket augmentation. Journal of Periodontology 2005; 76: 605-13.

17. Araujo MG, Linder E, Lindhe J. Effect of a xenograft on early bone formation in extraction sockets: an experimental study in dog. Clinical Oral Implants Research 2009;20: $1-6$.

18. Molly L, Vandromme H, Quirynen M, Schepers E, Adams JL, van Steenberghe D. Bone formation following implantation of bone biomaterials into extraction sites. Journal of Periodontology 2008; 79:1108-15.

19. Kim DM, Lim HC, Hong JY, Shin SI, Chung JH, Herr Y, Shin SY. Validity of Collagen Plugs for Ridge Preservation in a Canine Model. Implant Dent. 2017. Article in press 
20. Cho H, Jung HD, Kim BJ, et al. Complication rates in patients using absorbable collagen sponges in third molar extraction sockets: A retrospective study. J Korean Assoc Oral Maxillofac Surg. 2015; 41:26-9.

21. Hirota M, Mizuki N, Aoki S, et al. Efficacy of tooth extraction wound protection made of atelocollagen sponge (TRE-641): A pilot study in dogs. J Hard Tissue Biol. 2009;18:89-94.

22. Brodie JC, Goldie E, Connel G, et al. Osteoblast interactions with calcium phosphate ceramics modified by coating with type I collagen. J Biomed Mater Res A. 2005; 73:409-421.

23. Kim JS, Cha JK, Cho AR, et al. Acceleration of bone regeneration by BMP-2-loaded collagenated biphasic calcium phosphate in rabbit sinus. Clin Implant Dent Relat Res. 2015; 17:1103-1113.

24. Liu K.B., Huang K., Teng Y., Qu Y.Z., Cui W., Huang Z.F., Sun T.F., Guo X.D. Use of mineralized collagen bone graft substitutes and dorsal locking plate in treatment of elder metaphyseal comminuted distal radius fracture. Front. Mater. Sci. 2014; 8:87-94.

25. Spinato S, Galindo-Moreno P, Zaffe D, Bernardello F, Soardi CM. Is socket healing conditioned by buccal plate thickness? A clinical and histologic study 4 month after mineralized human bone allografting. Clin Oral Implants Res. 2014;25: e120-6.

26. Oghli AA, Steveling H. Ridge preservation following tooth extraction: A comparison between atraumatic extraction and socket seal surgery. Quintessence Int. 2010; 41:605-609.

27. Roman A, Cioban C, Stratul SI, et al. Ridge preservation using a new 3D collagen matrix: A preclinical study. Clin Oral Investig. 2015; 19:1527-1536.

28. Cardaropoli G, Arau'jo M, Hayacibara R, Sukekava F, Lindhe J. Healing of extraction sockets and surgically produced - augmented and non-augmented - defects in the alveolar ridge. An experimental study in the dog. J Clin Periodontol 2005; 32: 435-440. 